\title{
Ulcerative colitis-associated hospitalization costs: A population-based study
}

\author{
Stephanie Coward MSc ${ }^{1,2}$, Steven J Heitman MD ${ }^{1,2}$, Fiona Clement PhD², James Hubbard MSc ${ }^{1,2}$,

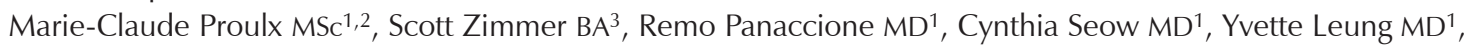 \\ Neel Datta $\mathrm{MD}^{4}$, Subrata Ghosh $\mathrm{MD}^{1}$, Robert P Myers $\mathrm{MD}^{1,2}$, Mark Swain $\mathrm{MD}^{1}$, Gilaad G Kaplan MD MPH${ }^{1,2}$
}

\begin{abstract}
S Coward, SJ Heitman, F Clement, et al. Ulcerative colitisassociated hospitalization costs: A population-based study. Can J Gastroenterol Hepatol 2015;29(7):357-362.
\end{abstract}

BACKGROUND: Hospitalization costs for ulcerative colitis (UC) following the introduction of infliximab have not been evaluated. OBJECTIVE: To study predictors of costs for UC patients who were hospitalized for a flare or colectomy.

METHODS: Population-based surveillance identified adults $(\geq 18$ years of age) admitted to hospital for UC flare or colectomy between 2001 and 2009 in the Calgary Health Zone (Alberta). Medical charts were reviewed and patients stratified into three admission types: responsive to inpatient medical therapy $(n=307)$; emergent colectomy $(n=227)$; and elective colectomy $(\mathrm{n}=208)$. The annual median cost with interquartile range (IQR) was calculated. Linear regression determined the effect of admission type on hospital charges after adjusting for age, sex, smoking, comorbidities, disease extent, medication use (eg, infliximab) and year. The adjusted cost increase was presented as the percent increase with 95\% CIs. Joinpoint analysis assessed for an inflection point in hospital cost after the introduction of infliximab.

RESULTS: Median hospitalization cost for UC flare, emergent colectomy and elective colectomy, respectively, were: $\$ 5,499$ (IQR $\$ 3,374$ to $\$ 8,904$ ), $\$ 23,698$ (IQR $\$ 17,981$ to $\$ 32,385$ ) and $\$ 14,316$ (IQR $\$ 11,932$ to $\$ 18,331$ ). Adjusted hospitalization costs increased approximately $6.0 \%$ annually ( $95 \%$ CI $4.5 \%$ to $7.5 \%$ ). Adjusted costs were higher for patients who underwent an elective colectomy (percent increase cost $179.8 \%$ [ $95 \%$ CI $151.6 \%$ to $211.1 \%$ ]) or an emergent colectomy (percent increase cost $211.1 \%$ [95\% CI $183.2 \%$ to $241.6 \%]$ ) than medically responsive patients. Infliximab in hospital was an independent predictor of increased costs (percent increase cost 69.5\% [95\% CI 49.2\% to $92.5 \%]$ ). No inflection points were identified.

CONCLUSION: Hospitalization costs for UC increased due to colectomy and infliximab.

Key Words: Costs; Hospitalization; Ulcerative colitis

\section{Les coûts d'hospitalisation associés à la colite ulcéreuse : une étude en population}

HISTORIQUE : Les coûts d'hospitalisation de la colite ulcéreuse (CU) n'ont pas été évalués depuis l'introduction de l'infliximab.

OBJECTIF : Étudier les prédicteurs de coûts pour les patients atteints de la CU hospitalisés en raison d'une récidive ou d'une colectomie.

MÉTHODOLOGIE : La surveillance en population a permis de recenser les adultes (de 18 ans et plus) hospitalisés en raison d'une récidive ou d'une colectomie de la CU entre 2001 et 2009 dans la zone de santé de Calgary, en Alberta. Les chercheurs ont examiné les dossiers des patients et les ont stratifiés en trois types d'hospitalisation : réponse à une pharmacothérapie pendant l'hospitalisation $(n=307)$, colectomie urgente $(n=227)$ et colectomie non urgente ( $n=208)$. Ils ont calculé le coût annuel médian et la plage interquartile (PIQ). Grâce à la régression linéaire, ils ont déterminé l'effet du type d'hospitalisation sur les coûts hospitaliers après rajustement en fonction de l'âge, du sexe, du tabagisme, des comorbidités, de l'étendue de la maladie, de l'utilisation de médicament (p. ex., infliximab) et de l'année. Ils ont présenté la hausse du coût rajusté sous forme d'augmentation du pourcentage, incluant le $95 \%$ IC et utilisé l'analyse à l'aide du modèle Joinpoint pour évaluer le point d'inflexion des coûts hospitaliers après l'introduction de l'infliximab.

RÉSULTATS : Les coûts d'hospitalisation médians d'une récidive, d'une colectomie urgente et d'une colectomie non urgente de la CU s'élevaient à 5499 \$ (PIQ 3374 \$ à 8904 \$), à 23698 \$ (PIQ 17981 \$ à 32385 \$) et à 14316 \$(PIQ 11932 \$ à 18331 \$), respectivement. Les coûts d'hospitalisation rajustés ont augmenté d'environ 6,0 \% par année $(95 \%$ IC $4,5 \%$ à $7,5 \%$ ). Les coûts rajustés étaient plus élevés chez les patients qui avaient subi une colectomie non urgente (coût d'augmentation en pourcentage de $179,8 \%$ [ $95 \%$ IC $151,6 \%$ à $211,1 \%$ ]) ou une colectomie urgente (coût d'augmentation en pourcentage de 211,1 \% [95 \% IC 183,2 \% à $241,6 \%]$ ) que chez ceux qui répondaient au traitement médical. L'infliximab à l'hôpital était un prédicteur indépendant d'augmentation des coûts (coût d'augmentation en pourcentage de 69,5 \% [95 \% IC 49,2 \% à $92,5 \%]$ ). Aucun point d'inflexion n'a été constaté.

CONCLUSION : Les coûts d'hospitalisation de la CU ont augmenté à cause de la colectomie et de l'infliximab.
$\mathrm{U}$ lcerative colitis (UC) is primarily diagnosed in late adolescence to early adulthood. The burden of UC is lifelong, and it afflicts individuals physically, mentally and financially (1). In North America, $0.25 \%$ of the population has UC and the incidence of UC appears to be increasing in many parts of the world (2). Despite advances in medical management, $15 \%$ of UC patients will undergo a total abdominal colectomy within 10 years of diagnosis (3). Colectomy is associated with considerable postoperative morbidity and impairs long-term quality of life (4-8). Overall, colectomy rates have decreased over time (3); however, while elective colectomy rates have steadily decreased, the rates of emergent colectomies have remained stable (9). These findings suggest that the health and economic burden of UC continues to be high.

The direct health care costs of inflammatory bowel disease (IBD) in the United States exceed USD $\$ 6$ billion annually (10). The average direct cost of UC has been estimated to be $>\$ 3,500$ per patient, with a large portion of these costs attributed to hospitalizations $(11,12)$. IBD hospitalizations account for nearly $\$ 395$ million in health care spending in Canada, and are predicted to increase $(11,12)$. Drivers of inpatient UC costs are multifactorial $(13)$, but include infliximab, which was shown in 2005 to reduce the risk of colectomy among UC patients who failed to respond to intravenous

${ }^{1}$ Department of Medicine, ${ }^{2}$ Community Health Sciences, and ${ }^{4}$ Surgery, University of Calgary, Calgary, Alberta; ${ }^{3}$ Alberta Health Services, Calgary, Alberta

Correspondence: Dr Gilaad G Kaplan, Departments of Medicine and Community Health Sciences, University of Calgary, 3280 Hospital Drive Northwest, 6D56, Calgary, Alberta T2N 4N1. Telephone 403-592-5015, fax 403-592-5090, e-mail ggkaplan@ucalgary.ca

Received for publication February 1, 2015. Accepted March 7, 2015 
corticosteroid therapy in hospital (14). However, comprehensive studies comparing hospitalization costs for UC pre and post the infliximab era are lacking.

Accordingly, we conducted a population-based study to identify the primary drivers of in-hospital cost for UC and to assess whether these factors changed following the introduction of infliximab.

\section{METHODS}

The present study was a population-based costing analysis of medical and surgical hospitalization admissions for adults (18 years of age) with $\mathrm{UC}$ in the Calgary Health Zone (CHZ) from January 1, 2001 to December 31, 2009.

\section{Data sources}

The Discharge Abstract Database used by Alberta Health Services (AHS) captures all diagnostic and procedural codes that occur during a hospital admission. AHS' Data Integration, Measurement and Reporting department (DIMR) identified patients coded using the International Classification of Diseases, Ninth Revision, Clinical Modification (ICD-9-CM) and the Tenth Revision (ICD-10-CM). All patients who were admitted with UC (ICD-9-CA code 556.9; ICD10-CM code K51) from January 1, 2001 to December 31, 2009 in the $\mathrm{CHZ}$ were captured; this method of identifying admissions has been previously validated (15). The CHZ contains the City of Calgary and $>20$ surrounding villages, towns, smaller cities and hamlets, and had a population of $1,408,606$ in 2011 . AHS is a single-payer, publically funded health care system that is responsible for all medical and surgical care within the $\mathrm{CHZ}$.

The total cost for each individual admission was attained from Activity and Costing - AHS Finance Department and through the Physician Claims Database. This database includes claims submitted for payment by Alberta physicians for services provided to registrants of the Alberta Health Care Insurance Plan, a universal plan that covers $>99 \%$ of Alberta residents (16). The total costs associated with each hospital admission account for both direct and indirect costs. Direct costs are all costs associated with direct patient care. These include - but are not limited to - nonphysician salaries, drugs, equipment depreciation cost, and the allocated costs for the nursing units and supporting care areas (ie, diagnostic imaging, cardiac labs, ambulatory services). Indirect costs are expenses that account for hospital overhead (eg, administration, support services, site utilities, human resources, information technology services, etc). Virtually all (99.7\%) of the admissions had matched finance data and were included in the analysis (the remaining $0.3 \%$ were excluded).

\section{Study population}

The DIMR database identified 1062 UC patients who had either a colectomy or flare admission. If patients had $>1$ UC-related admission, a single admission was randomly selected for analysis; this method of analysis has previously been validated (15). After chart review of the 1062 admissions, a total of 318 patients were excluded from the study because the charts were unavailable $(n=85)$, they had Crohn disease $(n=54)$, they did not have IBD $(n=42)$, they underwent a previous colectomy $(n=72)$ or UC was not the primary reason for admission $(n=65)$. The remaining 744 admissions were then stratified into one of three admission categories: responsive to inpatient medical therapy $(n=309)$, emergent colectomy during admission $(n=227)$ and elective colectomy during admission $(n=208)$. These admissions were then submitted to the AHS Finance Department for retrieval of costing data. Two additional admissions were excluded due to a lack of matching cost data, resulting in a study population of 742 patients.

\section{Data extraction}

Each patient underwent a comprehensive chart review to capture the following data: age at admission; residence; admit and discharge dates; duration of flare; date of UC diagnosis; disease extent; sex; smoking; UC-validated comorbidities $(17,18)$; UC medications including corticosteroids, 5-aminosalicylic acid, azathioprine, infliximab, adalimumab, budesonide and methotrexate; disease activity (stool frequency, blood in stool and hemoglobin level at admission); in-hospital complications both medical and surgical (assigned according to Clavien class [19]); and length of stay.

The data attained through the chart review were used to stratify patients into the three categories: responsive to medical management (flare); elective colectomy; or emergent colectomy. Patients were deemed responsive to inpatient medical therapy if they came to hospital with a UC-related flare and were discharged without surgery; during analysis, this was the referent group. Emergent colectomy was defined as a UC flare that required an unplanned colectomy. Elective colectomy was defined as admission for a scheduled colectomy.

\section{Statistical analysis}

Due to the skewed nature of the cost data, the annual median costs, with interquartile ranges for each of the admission categories (ie, responsive to inpatient medical management, elective colectomy, and emergent colectomy) were calculated. All costs were adjusted to 2013 Canadian dollars using the Consumer Price Index (20).

Linear regression was used to determine the effect that the different admission types had on the annual trend in hospital costs incurred for the admissions. Admission type was modelled as a categorical variable with 'responsive to inpatient medical management' as the referent level. The hospital costs were logarithmically transformed because of their skewed distribution and adjusted for the following covariates: year of admission as continuous variable; age stratified according to tercile ( 18 to 31,32 to 47 and $\geq 48$ ); sex; residence as defined as residing within or outside the $\mathrm{CHZ}$; smoking as current, ex-smoker, never or unknown; comorbidities as 0 or $\geq 1$; disease extent as pancolitis versus left-sided/undetermined; flare duration ( $<2$ weeks, two to eight weeks, $>8$ weeks or unknown); disease severity as presence of blood in stool or stool frequency ( $>5$ or $\leq 5$ days), and hemoglobin level at admission (>100 g/L versus $\leq 100 \mathrm{~g} / \mathrm{L}$ ); in-hospital complications; UC medications at admission (5-aminosalicylic acid, prednisone, azathioprine,) and/or during hospital (infliximab); and length of stay. All of these clinically relevant covariates were a priori included in the adjusted analysis.

Using linear regression, the annual cost increase was calculated for each UC admission type with the regression model including the adjustment for confounders. The beta coefficients were exponentiated to give the final annual percentage increase and their corresponding 95\% CIs. A Joinpoint analysis assessed for significant inflection points for both the mean and median cost of the aggregate data over the study period. The a priori analysis assessed for a significant cost inflection point after 2005 when infliximab was introduced (14). The statistical analysis was performed using SAS version 9.3 (SAS Institute, USA). The Joinpoint analysis was performed with Joinpoint Regression Program version 4.1.0 (21).

\section{RESULTS}

Patient characteristics stratified according to type of admission are presented in Table 1 . The median costs for each of the three admission types were: UC flare $\$ 5,499$ (interquartile range [IQR] $\$ 3,374$ to $\$ 8,904$ ), elective colectomy $\$ 14,316$ (IQR $\$ 11,932$ to $\$ 18,331$ ) and emergent colectomy $\$ 23,698$ (IQR $\$ 17,981$ to $\$ 32,385$ ). The inflationadjusted cost of all admissions increased by $6.0 \%$ (95\% CI $4.5 \%$ to $7.5 \%$ ) per year (Table 2). The median costs stratified according to admission type per year are presented in Figure 1. Significant Joinpoints were not identified in the median or mean costs.

UC patients who underwent an elective colectomy had a $179.8 \%$ (95\% CI $151.6 \%$ to $211.1 \%$ ) increase in cost versus those who were medically responsive to in-patient medical management after adjusting for covariates. Those who underwent emergent colectomies were significantly higher with a $211.1 \%$ (95\% CI $183.2 \%$ to $241.6 \%)$ increase in cost (Table 2).

Other independent predictors of hospitalization costs included: age ( $\geq 48$ years versus 18 to 31 years: $14.0 \%$ [95\% CI $4.2 \%$ to $24.6 \%$ ]); in-hospital complication (Clavien II/III/IV/V: 31.7\% [95\% CI 20.6\% 
TABLE 1

Characteristics of the study population

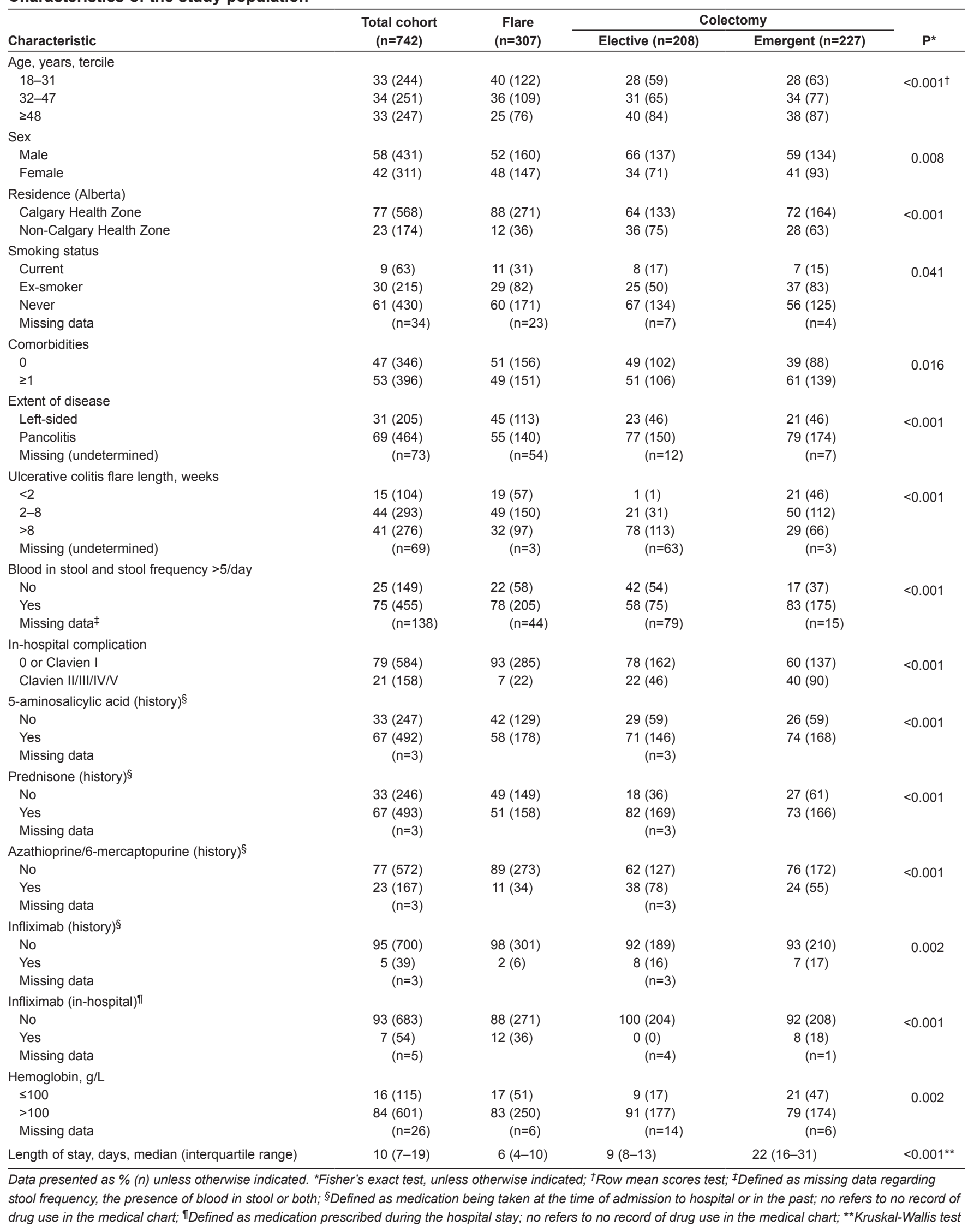


TABLE 2

Linear regression analysis of costs

\begin{tabular}{|c|c|c|c|}
\hline Variable & Comparison & Percent cost change $(95 \% \mathrm{Cl})$ & $\mathbf{P}$ \\
\hline Year & Per year & 6.0 (4.5 to 7.5$)$ & $<0.0001$ \\
\hline Admission type & Elective versus flare & 179.8 (151.6 to 211.1$)$ & $<0.0001$ \\
\hline Admission type & Emergency versus flare & 211.1 (183.2 to 241.6$)$ & $<0.0001$ \\
\hline Age, years & $\geq 48$ versus 18 to 31 & $14.0(4.2$ to 24.6$)$ & 0.004 \\
\hline Sex & Male versus female & $0.7(-5.7$ to 7.6$)$ & 0.826 \\
\hline Residence & Non- $\mathrm{CHZ}$ versus $\mathrm{CHZ}$ & $-7.2(-14.2$ to 0.5$)$ & 0.065 \\
\hline Smoking & Ex versus never & $-5.1(-12.2$ to 2.4$)$ & 0.178 \\
\hline Comorbidity & Yes versus no & $2.0(-4.7$ to 9.1$)$ & 0.565 \\
\hline Disease extent & Pancolits versus left-sided/undetermined & 11.4 (3.8 to 19.6$)$ & 0.003 \\
\hline Flare length ${ }^{\dagger}$ & 2 to 8 weeks versus $<2$ weeks & $8.9(-1.4$ to 20.2$)$ & 0.094 \\
\hline Flare length & $>8$ weeks versus $<2$ weeks & $8.9(-2.2$ to 21.2$)$ & 0.120 \\
\hline Blood in stool/stool frequency & $>5 /$ day versus $\leq 5 /$ day or no blood & $1.0(-7.4$ to 10.1$)$ & 0.821 \\
\hline Prednisone (history) & Yes versus no & $1.1(-6.6$ to 9.4$)$ & 0.795 \\
\hline Azathioprine (history) & Yes versus no & $-1.0(-9.1$ to 7.9$)$ & 0.825 \\
\hline Infliximab (history) & Yes versus no & $-9.9(-22.6$ to 4.9$)$ & 0.177 \\
\hline Infliximab (in-hospital) & Yes versus no & 69.5 (49.2 to 92.5$)$ & $<0.0001$ \\
\hline Hemoglobin & $>100$ versus $\leq 100$ & $-5.7(-13.8$ to 3.0$)$ & 0.192 \\
\hline Length of stay & Per day & $1.7(1.5$ to 1.9$)$ & $<0.0001$ \\
\hline
\end{tabular}

"Smoking included missing indicator level (not shown); †Flare length included missing indicator level (not shown). CHZ Calgary Health Zone (Alberta)

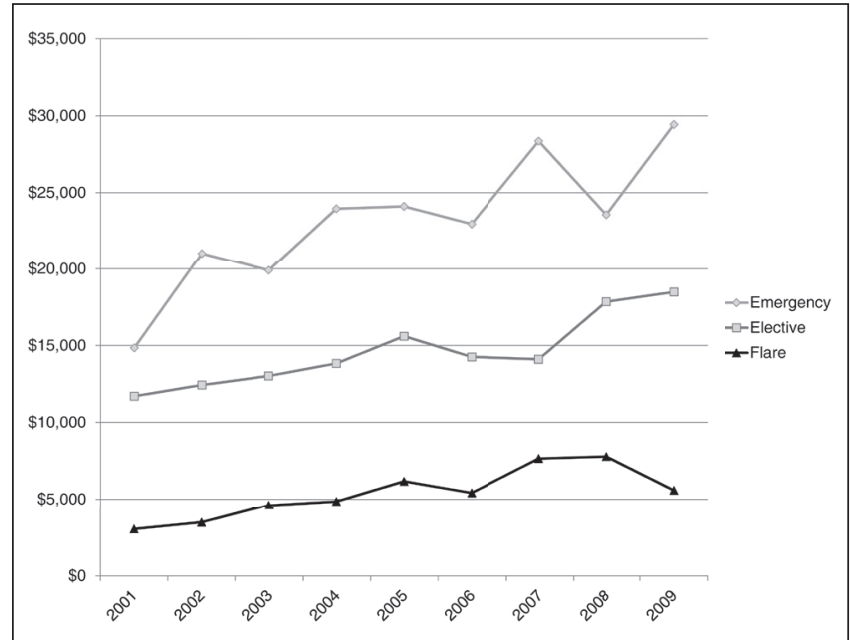

Figure 1) Temporal trends from 2000 to 2009 of median costs stratified according to each admission type: medically responsive flare, elective colectomy and emergent colectomy

to $43.8 \%$ ]); disease extent (pancolitis versus left-sided: $11.4 \%$ [95\% CI $3.8 \%$ to $19.6 \%]$ ); smoking (current versus never: $-11.6 \%$ [95\% CI $-21.4 \%$ to $-0.5 \%]$ ); infliximab prescribed in hospital $(69.5 \%$ [95\% CI $49.2 \%$ to $92.5 \%]$ ); and length of stay (1.7\% per day [95\% CI $1.5 \%$ to $1.9 \%])$.

\section{DISCUSSION}

It has previously been shown that during our study period, the rates of colectomy fell in the $\mathrm{CHZ}$, particularly the rate of elective colectomies (9). Despite the reduction in colectomies, in-hospital costs for all UC patients increased by $6.0 \%$ per year. After adjusting for disease severity, surgical admissions were associated with the highest magnitude of increased hospital costs. Emergent operations are associated with a greater length of stay and interventions performed in hospital due to higher occurrence of in-hospital complications and longer recovery periods $(5,7)$. Other drivers of cost were age, disease severity, in-hospital complications, length of stay, smoking status and in-hospital prescription of infliximab. By identifying some of the factors that contributed to the rising cost of UC care, we may consider alternative ways to mitigate these costs while providing appropriate patient care.

The present study evaluated the temporal trends of UC hospitalization costs in Canada since the introduction of infliximab in 2005 for the treatment of hospitalized UC patients refractory to intravenous corticosteroid therapy (14). Since 2005, infliximab has become a mainstay inhospital rescue agent for UC patients. A previous study demonstrated a sharp uptake of in-hospital prescriptions of infliximab in the CHZ (9). In the current study, infliximab was an independent risk factor for increasing hospital costs after adjusting for patient factors, disease severity and surgery. However, an expected inflection point of rising hospital costs after 2005 was not observed, which suggests that multiple factors contributed to increased hospital costs and/or money spent on infliximab may have been offset by alternative cost saving.

Moreover, infliximab is a modifiable cost factor that could prove to be a significant cost savings to hospital budgets. In Alberta, in-hospital use of infliximab is paid for by the hospital budget, whereas outpatient infliximab use is covered by provincial drug plans or by private drug coverage. Thus, timelier introduction of infliximab in the outpatient setting would avoid this expense in hospital and, additionally, may reduce the need for hospitalizations or lead to an elective colectomy. Among UC patients with fulminant colitis that requires infliximab in hospital, an alternative method of funding anti-tumour necrosis factor therapy that does not impact patient care should be implemented. Policy changes could lead to shifting in-hospital infliximab costs to drug insurance plans, or existing biologic infusion centres could be expanded to include in-hospital care where additional efficiencies may be generated.

In Canada, from 2000 to 2009, annual health care inflation rate rose by an average of approximately $1.6 \%$ per year (20). Costs for inhospital admissions for UC increased significantly faster than the 
inflation rate. This is due, in part, to the overall rise in health care costs that are outpacing the national inflation rate. Over time, hospitals have been admitting older and sicker patients with a greater number of chronic comorbidities, which has led to an increase in-hospital expenditures (22). In addition, medical technology and the labour force have been found to be significant cost drivers in the United States (23). In Alberta, the salary of unionized health care work force increased by $2 \%$ to $3 \%$ per year during our study period (24). Also, patients are staying longer in emergency departments due to bed shortages in hospital, and delays exceeding $12 \mathrm{~h}$ have been shown to increase cost by $11 \%(25)$. These factors may have played a part in the increasing expenditures.

A few limitations of our study should be considered (26). While we were able to explore both direct and indirect in-hospital costs, we were unable to differentiate whether the direct or indirect costs were the major cost drivers. In addition, we did not account for outpatient costs that patients incurred to the health care system. However, the purpose of the present study was to evaluate the evolution of in-hospital costs independent of the effect of outpatient management. By focusing on in-hospital costs, our study informs health care resource allocation planning for inpatient care, but is not generalizable to outpatient management. Because we undertook a retrospective chart review, some clinical factors, such as outpatient medication use, were missing in some patients. While the linkage to the AHS Finance Department that reported both direct and indirect hospital costs was $99.7 \%$ complete, indirect outpatient costs (eg, loss of work productivity) were not assessed in our study. Finally, administrative data were used to initially identify UC patients. While administrative data are subject to misclassification errors, we have previously validated this approach (15).

\section{CONCLUSION}

Studying temporal trends of in-hospital costs and identifying factors that drive these costs are important because UC is an expensive disease with a lifelong burden on patients and to the health care system. We studied a large population-based cohort of UC patients using rigorous study design including confirmation of clinical data through chart review and accurate linking to direct and indirect in-hospital costing data. We demonstrated that surgical admissions, infliximab and disease severity drives costs upward. Costs of hospitalizations for UC patients are steadily increasing and, thus, it is prudent to find ways to mitigate these costs without compromising patient care.

ACKNOWLEDGEMENTS: Dr Kaplan is supported through a New Investigator Award from the Canadian Institute of Health Research and a Population Health Investigator Award from Alberta-Innovates HealthSolutions. This study was based, in part, on data provided by Alberta Health. The interpretation and conclusions contained herein are those of the researchers and do not necessarily represent the views of the Government of Alberta. Neither the Government nor Alberta Health express any opinion in relation to this study. Stephanie Coward is supported by an Eyes High Doctoral Recruitment Scholarship from the University of Calgary.

DISCLOSURES: Dr Kaplan has served as a speaker for Janssen, ScheringPlough, Abbott, and UCB Pharma. He has participated in advisory board meetings for Jansen, Abbott, Merck, Schering-Plough, Shire, and UCB Pharma. Dr Kaplan has received research support from Merck, Abbott and Shire. Dr Panaccione has served as a speaker, a consultant and an advisory board member for Abbott Laboratories, Merck, Schering-Plough, Shire, Centocor, Elan Pharmaceuticals, and Procter and Gamble. He has served as a consultant and speaker for Astra Zeneca. He has served as a consultant and an advisory board member for Ferring and UCB. He has served as a consultant for Glaxo-Smith Kline and Bristol-Myers Squibb. He has served as a speaker for Byk Solvay, Axcan, Janssen and Prometheus. He has received research funding from Merck, Schering-Plough, Abbott Laboratories, Elan Pharmaceuticals, Procter and Gamble, Bristol-Myers Squibb and Millennium Pharmaceuticals. He has received educational support from Merck, ScheringPlough, Ferring, Axcan and Janssen. Dr Ghosh has served as a speaker for
Merck, Schering-Plough, Centocor, Abbott, UCB Pharma, Pfizer, Ferring, and Procter and Gamble. He has participated in ad hoc advisory board meetings for Centocor, Abbott, Merck, Schering-Plough, Proctor and Gamble, Shire, UCB Pharma, Pfizer and Millennium. He has received research funding from Procter and Gamble, Merck and ScheringPlough. Dr Cynthia Seow has served as a speaker for Janssen and Warner Chilcott. She has participated in advisory board meetings for Janssen and Abbvie. Dr Seow has received research support from Merck. Dr Yvette Leung has received research support from Janssen. She has served as a speaker for Jansen. She has participated in advisory board meetings for Abbott, Jansen and Shire. The other authors do not have relevant conflict of interests to declare.

AUTHOR CONTRIBUTIONS: Stephanie Coward was involved with the study concept and design, acquisition of data, analysis and interpretation of data, and drafting of the manuscript. Steven Heitman, Neel Datta, Mark Swain, Remo Panaccione, Cynthia Seow, Yvette Leung, Subrata Ghosh were involved with interpretation of data and critical revision of the manuscript. James Hubbard was involved with data analysis and critical revision of the manuscript. Marie-Claude Proulx, Scott Zimmer and Rob Myers were involved with acquisition of data, and interpretation of data. Fiona Clement was involved with statistical analysis and critical revision of the manuscript. Gilaad G Kaplan was involved with the study concept and design, statistical analysis, acquisition of data, analysis and interpretation of data, drafting of the manuscript, funding and study supervision.

FUNDING SOURCES: This research is supported by The Alberta IBD Consortium, which is funded by an AHFMR Interdisciplinary Team Grant. AHFMR is now Alberta Innovates - Health Solutions. The funders had no role in study design, data collection and analysis, decision to publish or preparation of the manuscript.

\section{REFERENCES}

1. Loftus EV Jr. Clinical epidemiology of inflammatory bowel disease: Incidence, prevalence, and environmental influences. Gastroenterology 2004;126:1504-17.

2. Molodecky NA, Soon IS, Rabi DM, et al. Increasing incidence and prevalence of the inflammatory bowel diseases with time, based on systematic review. Gastroenterology 2012;142:46-54

3. Frolkis AD, Dykeman J, Negron ME, et al. Risk of surgery for inflammatory bowel diseases has decreased over time: A systematic review and meta-analysis of population-based studies.

Gastroenterology 2013;145:996-1006.

4. Kaplan GG, Hubbard J, Panaccione R, et al. Risk of comorbidities on postoperative outcomes in patients with inflammatory bowel disease. Arch Surg 2011;146:959-64.

5. Kaplan GG, McCarthy EP, Ayanian JZ, et al. Impact of hospital volume on postoperative morbidity and mortality following a colectomy for ulcerative colitis. Gastroenterology 2008; 134:680-7.

6. Soon IS, Wrobel I, deBruyn JC, et al. Postoperative complications following colectomy for ulcerative colitis in children. J Pediatr Gastroenterol Nutr 2012;54:763-8.

7. de Silva S, Ma C, Proulx MC, et al. Postoperative complications and mortality following colectomy for ulcerative colitis Clin Gastroenterol Hepatol 2011;9:972-80.

8. de Zeeuw S, Ahmed Ali U, Donders RA, et al. Update of complications and functional outcome of the ileo-pouch anal anastomosis: Overview of evidence and meta-analysis of 96 observational studies. Int J Colorectal Dis 2012;27:843-53.

9. Kaplan GG, Seow CH, Ghosh S, et al. Decreasing colectomy rates for ulcerative colitis: A population-based time trend study. Am J Gastroenterol 2012;107:1879-87.

10. Kappelman MD, Rifas-Shiman SL, Porter CQ, et al. Direct health care costs of Crohn's disease and ulcerative colitis in US children and adults. Gastroenterology 2008;135:1907-13.

11. Bernstein CN, Longobardi T, Finlayson G, Blanchard JF. Direct medical cost of managing IBD patients: A Canadian populationbased study. Inflamm Bowel Dis 2012;18:1498-508.

12. Rocchi A, Benchimol EI, Bernstein CN, et al. Inflammatory bowel disease: A Canadian burden of illness review. Can J Gastroenterol 2012;26:811-7. 
13. Bernstein CN, Papineau N, Zajaczkowski J, et al. Direct hospital costs for patients with inflammatory bowel disease in a Canadian tertiary care university hospital. Am J Gastroenterol 2000;95:677-83.

14. Jarnerot G, Hertervig E, Friis-Liby I, et al. Infliximab as rescue therapy in severe to moderately severe ulcerative colitis: A randomized, placebo-controlled study. Gastroenterology 2005;128:1805-11.

15. Ma C, Crespin M, Proulx MC, et al. Postoperative complications following colectomy for ulcerative colitis: A validation study. BMC Gastroenterol 2012;12:39.

16. Data Disclosure Handbook. In: Alberta Health and Wellness; 2003:1-15.

17. Charlson ME, Pompei P, Ales KL, MacKenzie CR. A new method of classifying prognostic comorbidity in longitudinal studies: Development and validation. J Chron Dis 1987;40:373-83.

18. Deyo RA, Cherkin DC, Ciol MA. Adapting a clinical comorbidity index for use with ICD-9-CM administrative databases. J Clin Epidemiol 1992;45:613-9.

19. Dindo D, Demartines N, Clavien PA. Classification of surgical complications: A new proposal with evaluation in a cohort of 6336 patients and results of a survey. Ann Surg 2004;240:205-13.
20. Statistics Canada. Consumer Price Index. < www.statcan.gc.ca/tablestableaux/sum-som/101/cst01/econ09a-eng.htm> (Accessed August 3, 2014).

21. National Cancer Institute. Joinpoint Regression Program Version 4.1.0. $<$ http://surveillance.cancer.gov/joinpoint/> (Accessed April 1, 2014).

22. Steiner CA, Friedman B. Hospital utilization, costs, and mortality for adults with multiple chronic conditions, Nationwide Inpatient Sample, 2009. Prev Chronic Dis 2013;10:E62.

23. Hay JW. Hospital cost drivers: an evaluation of 1998-2001 statelevel data. Am J Managed Care 2003;9 Spec No 1:SP13-24.

24. Alberta Health Services. Collective Agreements and Bargaining Updates. <www.albertahealthservices.ca/8611.asp> (Accessed November 1, 2013).

25. Huang Q, Thind A, Dreyer JF, Zaric GS. The impact of delays to admission from the emergency department on inpatient outcomes. BMC Emerg Med 2010;10:16.

26. Molodecky NA, Panaccione R, Ghosh S, et al. Challenges associated with identifying the environmental determinants of the inflammatory bowel diseases. Inflamm Bowel Dis 2011;17:1792-9. 


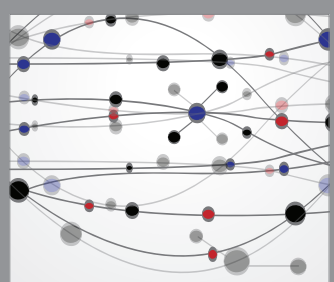

The Scientific World Journal
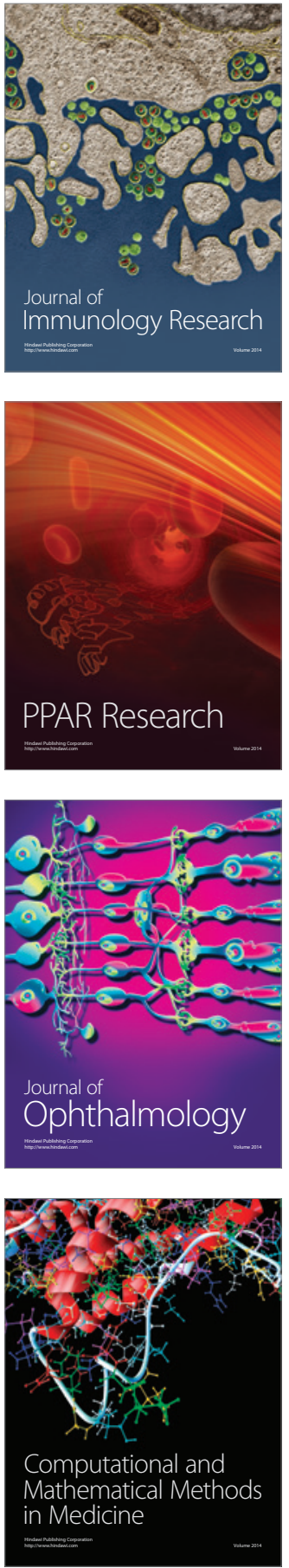

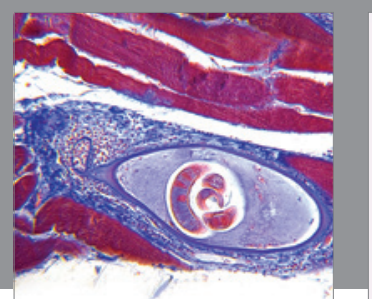

Gastroenterology Research and Practice

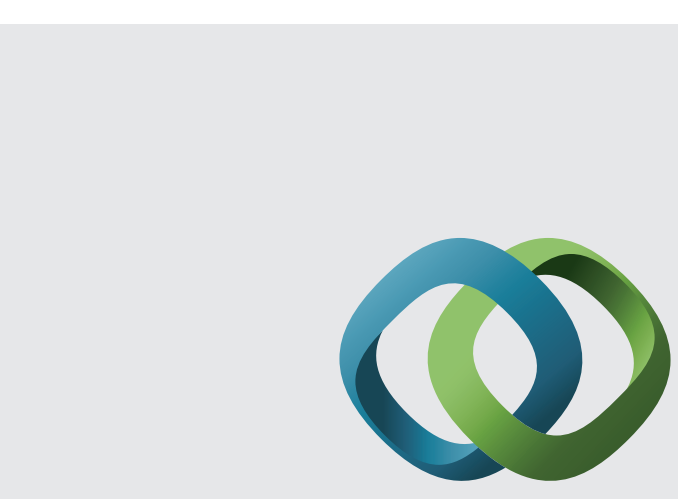

\section{Hindawi}

Submit your manuscripts at

http://www.hindawi.com
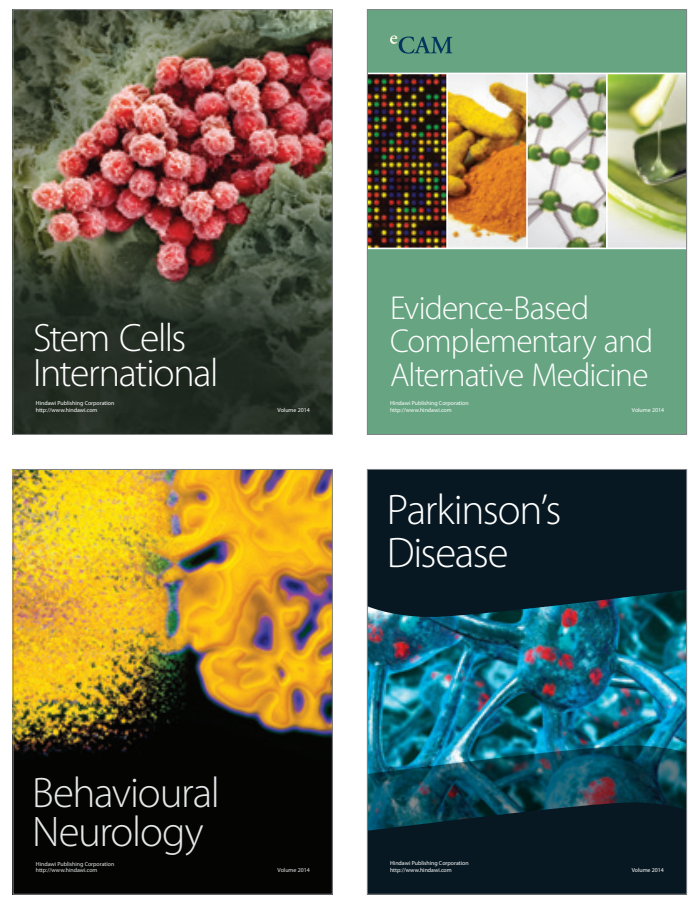
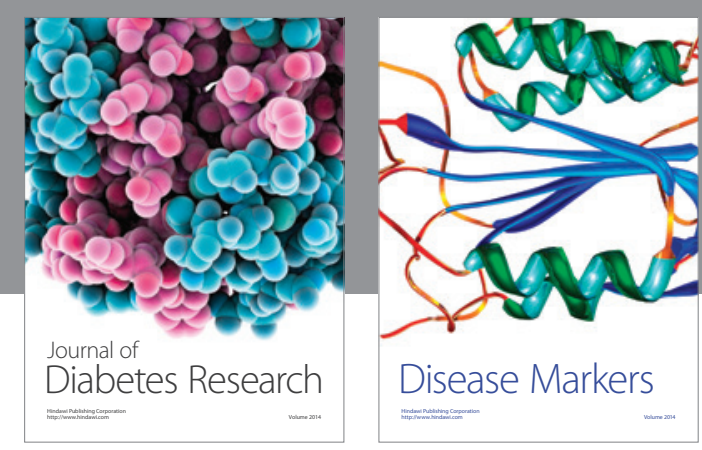

Disease Markers
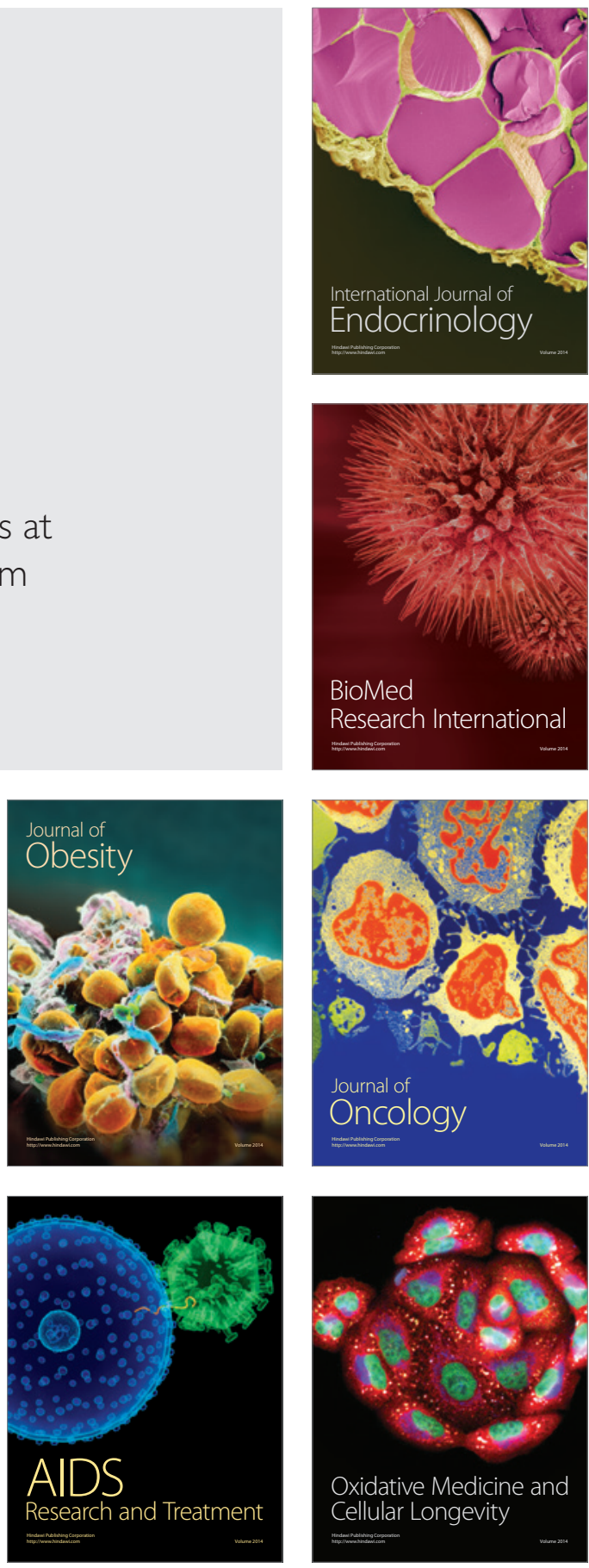